\title{
Социологический портрет
}

\section{РОССИЙСКИХ СПЕЦИАЛИСТОВ ПО АЮРВЕДИЧЕСКОЙ МЕДИЦИНЕ}

\author{
В.А. СЕРОВА ${ }^{1}$, О.В. СОРОКИН ${ }^{2}$ М.А. СУБОТЯЛОВ \\ ${ }_{1}^{1}$ Федеральное государственное автономное образовательное учреждение высшего образования «Новосибирский национальный \\ исследовательский государственный университет»: 630090, г. Новосибирск, ул. Пирогова, 2 \\ 2 Некоммерческая организация «Национальная аюрведическая медицинская ассоциация» \\ 3 Федеральное государственное бюджетное образовательное учреждение высшего образования «Новосибирский государственный \\ педагогический университет» Министерства образования и науки Российской Федерации: 630126, г. Новосибирск, ул. Вилюйская, д. 28
}

\section{Информация об авторах:}

Серова Валерия Анатольевна - студентка института медицины и психологии Федерального государственного автономного образовательного учреждения высшего образования «Новосибирский национальный исследовательский государственный университет» Министерства образования и науки Российской Федерации; тел.: +7 (999) 450-87-85; e-mail:v.serova@g.nsu.ru Сорокин Олег Викторович - К.М.Н., исполни- тельный директор Некоммерческой организации «Национальная аюрведическая медицинская ассоциация»; тел.: +7 (913) 916-67-09; e-mail:ceo@namaveda.org Суботялов Михаил Альбертович - Д.М.Н., профессор кафедры анатомии, физиологии и безопасности жизнедеятельности Федерального государственного бюджетного образовательного учреждения высшего образования «Новосибирский государственный педа- гогический университет» Министерства образования и науки Российской Федерации; доцент кафедры фундаментальной медицины Федерального государственного автономного образовательного учреждения высшего образования «Новосибирский национальный исследовательский государственный университет» Министерства образования и науки Российской Федерации; тел.: +7 (923) 119-6777; e-mail: subotyalov@yandex.ru

\section{PEз10ME}

Проведен анонимный социологический опрос 89 врачей и специалистов из разных городов и регионов Российской Федерации и стран СНГ, практикующих методы аюрведы. Показано, что данный контингент в социологическом отношении мало отличается от «обычных» коллег, имеет достаточный как общемедицинский, так и «аюрведический» стаж, на личном опыте убежден в эффективности аюрведических методов.

Ключевые слова: аюрведа, традиционная медицина, социология

Для цитирования: Серова В.А., Сорокин О.В., Суботялов М.А. Социологический портрет российских специалистов по аюрведической медицине. Медицинский совет. 2018; 21: 210-214. DOI: https://doi.org/10.21518/2079-701X-2018-21-210-214.

Конфликт интересов: авторы заявляют об отсутствии конфликта интересов.

\section{Sociological portrait}

\section{OF RUSSIAN SPECIALISTS IN AYURVEDIC MEDICINE}

\author{
Valeria A. SEROVA ${ }^{1}$, Oleg V. SOROKIN², Mikhail A. SUBOTIALOV ${ }^{1,3}$ \\ ${ }^{1}$ Federal State Autonomous Educational Institution of Higher Education «Novosibirsk National Research State University»: 630090, \\ Novosibirsk, Pirogova Street, 2 \\ 2 Non-profit organization «National Ayurvedic Medical Association» \\ ${ }^{3}$ Federal State Budgetary Educational Institution of Higher Education «Novosibirsk State Pedagogical University» of the Ministry of \\ Education and Science of the Russian Federation: 630126, Novosibirsk, Vilyuyskaya St., 28
}

\section{Author credentials:}

Valeria Anatolievna Serova - a student of the Institute of Medicine and Psychology of the Federal State Autonomous Educational Institution of Higher Education «Novosibirsk National Research State University» of the Ministry of Education and Science of the Russian Federation; tel: +7 (999) 450-87-85; e-mail:v.serova@g.nsu.ru Oleg Viktorovich Sorokin - Candidate of Medical Sciences, Executive Director of the non-profit organization «National Ayurvedic Medical Association»; tel: +7 (913) 916-6709; e-mail:ceo@namaveda.org

Mikhail Subotialov Albertovich - Doctor of Medical Sciences, Professor of the Department of Anatomy, Physiology and Life Safety of the Federal State Educational Institution of Higher Education «Novosibirsk State

Pedagogical University» of the Ministry of
Education and Science of the Russian Federation; Associate Professor of the Department of Fundamental Medicine of the Federal State Autonomous Educational Institution of Higher Education «Novosibirsk National Research State University» of the Ministry of Education and Science of the Russian Federation; tel: +7 (923) 119-67-77; e-mail: subotyalov@yandex.ru

\section{ABSTRACI}

An anonymous sociological survey of 89 doctors and specialists from different cities and regions of the Russian Federation practicing ayurvedic methods was conducted. It is shown that this contingent in sociological terms differs little from «ordinary» colleagues, they have sufficient both general medical and «ayurvedic» experience, and are convinced by personal experience of the effectiveness of Ayurvedic methods.

Keywords: ayurveda, traditional medicine, sociology

For citing: Serova V.A., Sorokin O.V., Subotialov M.A. Sociological portrait of russian specialists in ayurvedic medicine Meditsinsky Sovet. 2018; 21: 210-214 DOI: https://doi.org/10.21518/2079-701X-2018-21-210-214. 


\section{ВВЕДЕНИЕ}

В настоящее время в России отмечается возрастание интереса к традиционным системам оздоровления. Одной из наиболее развитых и популярных в мире традиционных медицинских систем является аюрведа [13]. Хотя аюрведические методы используются очень давно, применение аюрведы в России началось относительно недавно [12]. При этом за последние годы защищено 2 диссертации, посвященные изучению аюрведической медицины [5, 13], выпущены монографии и учебные пособия [2, 3, 11, 14], проводятся научные исследования аюрведических методов и средств $[6,8-10,15,16]$, в различных городах регулярно проходят конференции по аюрведической медицине. В течение нескольких лет идут исследования аюрведических лекарственных растений $[1,4]$. Также в течение последних 15 лет на базе различных высших учебных заведений России проводится обучение аюрведе врачей и специалистов по оздоровлению.

В связи с вышесказанным представляет интерес изучить медико-социологический портрет российских специалистов по аюрведе.

\section{МАТЕРИАЛЫ И МЕТОДЫ}

В 2018 г. по специально разработанной анкете проведен анонимный социологический опрос 89 врачей и специалистов, практикующих остеопатию, из разных городов и регионов России и ближнего зарубежья. Выбор ответов на вопросы был опциональным, и обследуемые могли давать ответы не на все вопросы.

\section{РЕЗУЛЬТАТЫ ИССЛЕДОВАНИЯ}

Работ по медико-социологическому обследованию специалистов и врачей, занимающихся традиционной медициной, мало. Профессором Д.Е. Моховым была проведена работа, посвященная обследованию специалистов, занимающихся остеопатией в России [7]. Часть результатов нашего обследования были сопоставлены с его данными.

Из 89 опрошенных выделено две группы специалистов (табл. 1), использующих в своей лечебно-оздоровительной деятельности принципы аюрведы: лица, имеющие высшее медицинское образование (25 человек) и лица с иным образованием (64 человека), в том числе разделенных по гендерным особенностям.

В обеих группах значительно преобладали женщины, что, по нашему мнению, связано с большей вовлеченностью женщин в изучение ведической культуры, йоги и восточных практик. В то же время, по данным Д.Е. Мохова, среди остеопатов преобладают мужчины, так как проведение остеопатических процедур связано с необходимостью иметь значительную физическую подготовку, что коррелирует со статистикой по другим специальностям, связанным с мануальными техниками.

Был проведен анализ распределения специалистов по возрастным категориям (табл. 2).
Таблица 1. Распределение обследуемых по полу Table 1. Distribution of subjects by sex

\begin{tabular}{c|c|c} 
Пол & Врачи (24) & специалисты (61) \\
\hline M & $7(29,17 \%)$ & $17(27,87 \%)$ \\
\hline Ж & $17(70,83 \%)$ & $44(72,13 \%)$
\end{tabular}

Таблица 2. Распределение обследуемых по возрасту Table 2. Distribution of subjects by age

\begin{tabular}{c|c|c} 
Возраст & Врачи (24) & Специалисты (60) \\
\hline $20-29$ & $3(12,50 \%)$ & $3(5,00 \%)$ \\
\hline $30-39$ & $2(8,33 \%)$ & $12(20,00 \%)$ \\
\hline $40-49$ & $13(54,17 \%)$ & $19(31,67 \%)$ \\
\hline $50-59$ & $6(25,00 \%)$ & $22(36,67 \%)$ \\
\hline Старше 60 & - & $4(6,67 \%)$
\end{tabular}

Из приведенных данных видно, что большая доля врачей, интересующихся методами аюрведической медицины, приходится на возраст 40-49 лет (больше половины выборки). Именно в этом возрасте врачи, как правило, закрывают высшую или первую категорию по своей специальности, достигнув максимального профессионального развития и начинают искать новые области применения своих компетенций. На возрастные коридоры 20-29 лет и 30-39 лет суммарно приходится около 20\% выборки, что, по-видимому, связано со смещением акцента в этом периоде на приобретение профессиональных навыков в рамках своей медицинской специальности, чтобы состояться как специалисту и сформировать профессиональный авторитет, поэтому свободного времени на овладение новыми знаниями остается мало. Снижение доли врачей в возрасте старше 50 лет до 25\% может указывать на более низкую способность к восприятию новых знаний в этом возрасте и определенный профессиональный консерватизм. Сходная тенденция отмечается и в исследовании социального портрета врачей-остеопатов. В группе специалистов без высшего медицинского образования, напротив, видна тенденция к постепенному увеличению доли интересующихся аюрведой в сторону более старшего возраста. Более 60\% приходится на возраст 40-59 лет, что может быть связано с переосмыслением своей профессиональной принадлежностью и желанием пройти профессиональную переориентацию с формированием новых компетенций в области оздоровительной деятельности.

В исследовании приняли участие специалисты из 9 федеральных округов. По нашим данным, наибольшее число специалистов, изучающих и практикующих методы аюрведы, находится в Центральном и Сибирском федеральных округах, что суммарно составило более $60 \%$ выборки (табл. 3). По нашему мнению, указанная закономерность связана не с особенностями открытости к новым знаниям в разных регионах, а с наличием двух наиболее востребованных в среде специалистов, образовательных центров, обучающих основам аюрведической медицины в Москве и Новосибирске. 
Таблица 3. Распределение обследуемых по месту проживания Table 3. Distribution of respondents by place of residence

\begin{tabular}{l|c|c}
\multicolumn{1}{c|}{ Субьект } & Врачи (24) & Специалисты (57) \\
\hline Сибирский Ф0 & $7(29,17 \%)$ & $14(24,56 \%)$ \\
\hline Центральный Ф0 & $5(20,83 \%)$ & $20(35,09 \%)$ \\
\hline Приволжский Ф0 & $4(16,67 \%)$ & $3(5,26 \%)$ \\
\hline Северо-Западный Ф0 & $2(8,33 \%)$ & $6(10,53 \%)$ \\
\hline Дальневосточный Ф0 & $2(8,33 \%)$ & $2(3,51 \%)$ \\
\hline Уральский Ф0 & $1(4,17 \%)$ & $3(5,26 \%)$ \\
\hline Южный Ф0 & $1(4,17 \%)$ & $1(1,75 \%)$ \\
\hline Северо-Кавказский Ф0 & $1(4,17 \%)$ & - \\
\hline Крымский ФО & - & $2(3,51 \%)$ \\
\hline $\begin{array}{l}\text { Казахстан, Сербия, Молдавия, } \\
\text { Белоруссия }\end{array}$ & & $6(10,53 \%)$
\end{tabular}

Таблица 4. Количество детей у обследуемых

Table 4. Number of children in the surveyed

\begin{tabular}{c|c|c} 
Количество детей & Врачи (23) & Специлисты (56) \\
\hline 0 & $5(21,74 \%)$ & $13(23,21 \%)$ \\
\hline 1 & $7(30,43 \%)$ & $16(28,57 \%)$ \\
\hline 2 & $8(34,78 \%)$ & $23(41,07 \%)$ \\
\hline 3 & $2(8,70 \%)$ & $3(5,36 \%)$ \\
\hline 4 & - & - \\
\hline 5 & $1(4,35 \%)$ & - \\
\hline 6 & - & $1(1,79 \%)$
\end{tabular}

Наше предположение о том, что социальная ответственность перед семьей может стать препятствием при смене профессиональной деятельности и началом практики в области аюрведы не нашло подтверждения. Более двух третей респондентов имеют семью с одним или двумя детьми (табл. 4). Эти показатели могут свидетельствовать о более стабильном социальном положении данных специалистов.

Интересно отметить, что у врачей, использующих методы аюрведы, родственники лишь частично разделяют их интерес к традиционным системам оздоровления (табл. 5). В то время как в среде специалистов без медицинского образования родственники в большей мере полностью разделяют и поддерживают интерес к аюрведе.

Лишь пятая часть ощущает нейтральное отношение близких людей, и менее 5\% испытывают негативное отношение родственников к выбранному профессиональному пути.

Больше половины опрошенных отмечают позитивное отношение коллег к их деятельности (табл. 6). Отрицательная оценка применения аюрведических подходов со стороны коллег отмечается в единичных случаях. Среди врачей треть отмечает нейтральный подход коллег к их деятельности. Здесь можно говорить, по крайней мере, о том, что подавляющее большинство опрошенных не ощущают препятствий для своей деятельности и не подвергаются осуждению коллегами по причине разных взглядов на методы лечения и оздоровления. Схожее распределение мнений коллег опрошенных специалистов отмечается и в обследовании врачей-остеопатов.

По нашим данным, знакомство с аюрведой у врачей и специалистов происходило разными путями. Если специалисты начинали изучать аюрведу через знакомство с аюрведическими препаратами и маркетинговую деятельность фармкомпаний, которые занимаются дистрибуцией аюрведических препаратов, то врачи начинали изучать аюрведу через изучение профессиональной литературы и посещение профессиональных курсов повышения квалификации (табл. 7).

Единичными случаями для обеих групп явились знакомства через коллег, практикующих аюрведу, в то же время, по данным Д.Е. Мохова, половина респондентов познакомились с остеопатией через коллег, практикующих ее.

Среди врачей больше половины, а среди специалистов большинство опрошенных утверждают, что положительно отнеслись к аюрведическим методикам в момент знакомства (табл. 8). В исследовании Д.Е. Мохова отношение врачей-остеопатов к их специальности на момент знакомства было несколько иным: лишь треть сразу высказала доверие к методике, больше половины людей усомнились в эффективности метода и некоторые совершенно не испытывали доверия.

Таблица 5. Отношение родственников респондентов к деятельности обследуемых

Table 5. Attitude of respondents' relatives to the activities of the respondents

\begin{tabular}{l|c|c}
$\begin{array}{c}\text { Онношение близких } \\
\text { и родственников } \\
\text { к деятельности опрошенного }\end{array}$ & Врачи (24) & Специалисты (59) \\
\hline Полностью принимают & $8(33,33 \%)$ & 26 (44,07\%) \\
\hline Частично разделяют & $11(45,83 \%)$ & $19(32,20 \%)$ \\
\hline Нейтральны & $4(16,67 \%)$ & $11(18,64 \%)$ \\
\hline Негативно относятся & $1(4,17 \%)$ & $3(5,08 \%)$ \\
\hline Полностью отрицают & - & -
\end{tabular}

Таблица 6. Отношение коллег респондентов к деятельности обследуемых

Table 6. Attitude of respondents' colleagues to the activities of the respondents

\begin{tabular}{l|c|c}
$\begin{array}{c}\text { Отношение коллег } \\
\text { к деятельности опрошенного }\end{array}$ & Врачи (24) & Специалисты (48) \\
\hline Полностью принимают & $3(12,50 \%)$ & $9(18,75 \%)$ \\
\hline Частично разделяют & $12(50,00 \%)$ & $29(60,42 \%)$ \\
\hline Нейтральны & $8(33,33 \%)$ & $8(16,67 \%)$ \\
\hline Негативно относятся & - & $2(4,17 \%)$ \\
\hline Полностью отрицают & $1(4,17 \%)$ & -
\end{tabular}


Таблица 7. Обстоятельства знакомства с аюрведой

Table 7. Circumstances of familiarity with Ayurveda

\begin{tabular}{l|c|c}
\multicolumn{1}{c|}{ Обстоятельства } & Врачи (22) & Специалисты (60) \\
\hline $\begin{array}{l}\text { Через коллег, практикующих } \\
\text { аюрведу }\end{array}$ & $1(4,55 \%)$ & $7(11,67 \%)$ \\
\hline $\begin{array}{l}\text { Через фармацевтические } \\
\text { компании }\end{array}$ & $3(13,64 \%)$ & $19(31,67 \%)$ \\
\hline $\begin{array}{l}\text { Через курсы повышения } \\
\text { квалификации, книги, интернет }\end{array}$ & $11(50,00 \%)$ & $17(28,33 \%)$ \\
\hline $\begin{array}{l}\text { Через лекции специалистов } \\
\text { По иному стечению }\end{array}$ & $3(13,64 \%)$ & $6(10,00 \%)$ \\
\hline обстоятельств & $4(18,18 \%)$ & $11(18,33 \%)$ \\
\hline
\end{tabular}

Таблица 8. Отношение к аюрведе на момент знакомства

Table 8. Attitude to Ayurveda at the time of acquaintance

\begin{tabular}{l|c|c}
$\begin{array}{c}\text { Отношение к аюрведе } \\
\text { на момент знакомства }\end{array}$ & Врачи (24) & Специалисты (62) \\
\hline Настороженное & $5(20,83 \%)$ & $8(12,90 \%)$ \\
\hline Равнодушное & $4(16,67 \%)$ & $3(4,84 \%)$ \\
\hline Позитивное & $15(62,50 \%)$ & $51(82,26 \%)$
\end{tabular}

В качестве причины изучения аюрведы более половины врачей отмечают приобретение новых профессиональных компетенций, позволяющих добиваться лучших результатов в лечении своих пациентов (табл. 9). В то же время для специалистов эта причина является равнозначной по сравнению с другими причинами, в частности с получением значимых для своего здоровья результатов лечения методами аюрведы и с общим интересом к расширению своего кругозора.

В исследовании профессора Д.Е. Мохова отмечено также, что большинство остеопатов в качестве причины углубления в эту специальность назвали наибольшую эффективность, безвредность и уникальность подхода. Такое распределение мнений можно объяснить глубоким пониманием врачами принципов лечения пациента в разных медицинских системах, что позволяет им на собственном опыте делать выводы об эффективности тех или иных подходов.

Больше половины врачей имеют опыт работы по основной специальности более 15 лет, но также значительная часть имеет опыт работы до 5 лет (табл. 10). Среди специалистов подавляющее большинство имеет опыт работы по основной специальности до 10 лет, из них около половины - молодые специалисты с опытом работы менее 5 лет. В исследовании медико-социального образа врачей-остеопатов отмечено, что подавляющее большинство опрошенных имеют общемедицинский стаж более 10 лет. Это сходно с нашими результатами и может означать наиболее зрелый, осознанный выбор аюрведы как поля новых знаний и практической деятельности. Тот факт, что достаточно много молодых специалистов из обеих групп отдают предпочтение аюрведе, говорит о востребованности данного направления среди молодежи.
Большинство среди опрошенных владеют английским языком на достаточном для чтения книг уровне (табл. 11). Но литературу по аюрведе на английском языке читают лишь четверть медиков и одна пятая часть специалистов. Трое специалистов читают аюрведическую литературу на санскрите (табл. 12).

Таблица 9. Причины изучения аюрведы

Table 9. Reasons for studying Ayurveda

\begin{tabular}{l|c|c}
\multicolumn{1}{c|}{ Группа причин } & Врачи (22) & Специалисты (59) \\
\hline $\begin{array}{l}\text { Поиск излечения для себя/ } \\
\text { близких }\end{array}$ & 5 (22,73\%) & $18(30,51 \%)$ \\
\hline Поиск преимуществ аюрведы & $11(50,00 \%)$ & $21(35,59 \%)$ \\
\hline $\begin{array}{l}\text { Интерес и тяга к расшире- } \\
\text { нию кругозора }\end{array}$ & $6(27,27 \%)$ & 20 (33,90\%) \\
\hline
\end{tabular}

Таблица 10. Стаж работы по основной специальности Table 10. Length of service in the main specialty

\begin{tabular}{c|c|c}
$\begin{array}{c}\text { Общий стаж работы } \\
\text { по основной специальности }\end{array}$ & Врачи (24) & Специалисты (57) \\
\hline $1-5$ лет & $6(25,00 \%)$ & $22(37,93 \%)$ \\
\hline $6-10$ лет & $2(8,33 \%)$ & $12(20,69 \%)$ \\
\hline $11-15$ лет & $2(8,33 \%)$ & $7(12,07 \%)$ \\
\hline $16-20$ лет & $5(20,83 \%)$ & $8(13,79 \%)$ \\
\hline $21-25$ лет & $5(20,83 \%)$ & $3(5,17 \%)$ \\
\hline $26-30$ лет & $2(8,33 \%)$ & $3(5,17 \%)$ \\
\hline Более 30 лет & $2(8,33 \%)$ & $3(5,17 \%)$ \\
\hline
\end{tabular}

Таблица 11. Владение английским языком респондентами Table 11. Knowledge of English by respondents

\begin{tabular}{l|c|c}
\multicolumn{1}{c|}{$\begin{array}{c}\text { Владение } \\
\text { ангийским языком }\end{array}$} & Врачи (24) & Специалисты (60) \\
\hline Не владею & $2(8,33 \%)$ & $10(16,67 \%)$ \\
\hline $\begin{array}{l}\text { Могу читать и переводить } \\
\text { со словарем }\end{array}$ & $12(50,00 \%)$ & $16(26,67 \%)$ \\
\hline $\begin{array}{l}\text { Понимаю язык, но не говорю } \\
\text { на нем }\end{array}$ & $1(4,17 \%)$ & $5(8,33 \%)$ \\
\hline $\begin{array}{l}\text { Понимаю язык и с затрудне- } \\
\text { ниями изьясняюсь на нем }\end{array}$ & $6(25,00 \%)$ & $17(28,33 \%)$ \\
\hline Свободно владею & $3(12,50 \%)$ & $12(20,00 \%)$
\end{tabular}

Таблица 12. Использование иностранного языка для изучения аюрведических книг

Table 12. Use of a foreign language to study Ayurvedic books

\begin{tabular}{l|c|c}
\multicolumn{1}{c|}{ язык } & Врачи (23) & Специалисты (63) \\
\hline Русский & $23(100,00 \%)$ & $61(96,83 \%)$ \\
\hline Английский & $6(26,09 \%)$ & $12(19,05 \%)$ \\
\hline Санскрит & - & $3(4,76 \%)$
\end{tabular}


Таблица 13. Место работы врачей

Table 13. Place of physicians' work

\begin{tabular}{l|c}
\multicolumn{1}{c|}{ Место работы врачей } & \% опрошенных (22) \\
\hline Государственные медицинские организации & $6(27,27 \%)$ \\
\hline Частные медицинские организации & $16(72,73 \%)$
\end{tabular}

Таблица 14. Страна обучения аюрведе

Table 14. Country of Ayurveda training

\begin{tabular}{l|c|c} 
Страна, в которой обучался & Врачи (24) & Специалисты (59) \\
\hline Россия & $24(100,00 \%)$ & $54(91,53 \%)$ \\
\hline Индия, Непал & - & $4(6,78 \%)$ \\
\hline Латвия & - & $1(1,69 \%)$
\end{tabular}

Большинство врачей работают в частных медицинских организациях, четверть из них ведут прием и по аюрведе, один из врачей занимается только традицион- ной медициной (табл. 13). В исследовании Д.Е. Мохова отмечено, что остеопатический прием в России осуществляется в медицинских организациях разных типов, в том числе в государственных и частных клиниках. Мы можем объяснить такое распределение кадров тем, что в России аюрведа официально не признана как отрасль медицины, несмотря на то что ВОЗ давно признала традиционную медицину эффективной и делает акцент на необходимости вести исследования и принимать государственные программы обучения по этим направлениям (табл. 14).

\section{ВЫВОД}

Таким образом, врачи и специалисты в области аюрведы в социологическом отношении мало отличаются от остальных коллег, имеют достаточный общемедицинский и аюрведический стаж, на личном опыте убеждены в эффективности аюрведических лечебно-оздоровительных методов.

\section{ЛИTEPATYPA/REFERENCES}

1. Айзман Р.И., Корощенко Г.А., Гайдарова А.П. и др. Механизмы действия порошка корневища растения Curcuma longa на углеводный обмен при аллоксан-индуцированном сахарном диабете у крыс. Бюллетень сибирской медицины. 2014; 13(6): 105-112. [Aizman R.I., Koroschenko G.A., Gaidarova A.P., et al. Mechanisms of action of Curcuma longa plant rhizome powder for carbohydrate metabolism in alloxane-induced diabetes mellitus in rats. [Byulleten' sibirskoy mediciny] Bulletin of Siberian medicine. 2014; 13(6): 105-112.] (In Russ).

2. Ветров И.И., Кузьменко А.В. Основы аюрведи ческой медицины. СПб: Святослав, 2003. 352 c. [Vetrov I.I., Kuzmenko A.V. Fundamentals of Ayurvedic medicine. St. Petersburg: Svyatoslav, 2003. 352 p.] (In Russ).

3. Ветров И.И., Сорокина Ю.В. Основы аюрведи ческой фитотерапии. СПб.: ООО

Аюрведический центр Дханвантари, 2012. 847 c. [Vetrov I.I., Sorokina Yu.V. Fundamentals of Ayurvedic phytotherapy. St. Petersburg: Dhanvantari Ayurvedic Center LLC, 2012. 847 p.] (In Russ).

4. Гравель И.В., Скибина А.С., Кузьменко А.Н. и др. Изучение химического состава корней спаржи кистевидной. Вестник Московского университета. Серия 2: Химия. 2017; 58(4): 199-203. [Gravel I.V., Skibina A.S., Kuzmenko A.N., et al. Study of the chemical composition of asparagus roots of the cyst-shaped asparagus. [Vestnik moskovskogo universiteta] MSU Vestnik. Series 2: Chemistry. 2017; 58(4): 199203.] (In Russ).

5. Дружинин В.Ю. «Чарака-самхита»: история формирования, структура, учения и современное значение: автореф. дис. ... канд. мед. наук. M., 2017. 24 c. [Druzhinin V.Yu. «CharakaSamkhita»: history of formation, structure, teachings and modern meaning: author's abstract ... cand. of medical sciences. M., 2017. 24 p.] (In Russ).

6. Кузнецов В.Н. Аюрведические препараты в практике спортивной медицины. Вестник Южно-Уральского государственного университета. 2006; 3: 215-216. [Kuznetsov V.N. Ayurvedic drugs in practice of sports medicine. [Vestnik Yuzhno-Ural'skogo gosudarstvenno- go universiteta.] Bulletin of the South Ural State University. 2006; 3: 215-216.] (In Russ).

7. Мохов Д.Е., Малков С.С. Медико социологический портрет современного российского врача-остеопата. Мануальная терапия. 2009; 4(36): 33-39. [Mokhov D.E., Malkov S.S. Medical and sociological portrait of a modern Russian osteopath. [Manual'naya terapiya] Manual therapy. 2009; 4(36): 33-39.] (In Russ).

8. Семёнова Л.Г, Бобкова А.С., Бобровницкий И.П., и др. Опыт применения аюрведической диагностики в восстановительной медицине для раннего выявления стрессогенных расстройств у студентов. Вестник восстановительной медицины. 2010; 4: 24-28.

[Semyonova L.G., Bobkova A.S., Bobrovnitsky I.P., et al. Experience of application of Ayurvedic diagnostics in rehabilitation medicine for early detection of stressful disorders in students. [Vestnik vosstanovitel'noy mediciny] Journal of Restorative Medicine and Rehabilitation. 2010; 4: 24-28.] (In Russ)

9. Семёнова, Л.Г., Бобровницкий И.П., Бобкова А.С., и др. Сравнительное изучение диагностической информативности аюрведического и полипараметрического методов при интегральной оценке состояния здоровья студентов. Вестник восстановительной медицины. 2012; 6: 8-11. [Semyonova, L.G., Bobrovnitsky I.P., Bobkova A.S., et al. Comparative Study of Diagnostic Informativity of Ayurvedic and Polyparametric Methods in Integral Assessment of Students' Health. [Vestnik vosstanovitel'noy mediciny] Journal of Restorative Medicine and Rehabilitation. 2012; 6: 8-11.] (In Russ).

10. Сорокин О.В., Суботялов М.А. Опыт научнопрактической разработки АПК «ВедаПульс» на основе алгоритмов Аюрведической медицины. Первый Российский Конгресс по комплементарной медицине: Материалы конгресса, М.: НИПКЦ Восход-А, 2013: 216-217. [Sorokin O.V., Subotyalov M.A. Experience of scientific and practical development of HSC «VedaPulse» on the basis of Ayurvedic medicine algorithms. First Russian Congress on Complementary Medicine: Materials of the
Congress, Moscow: Voshod-A, 2013: 216-217.] (In Russ).

11. Суботялов М.А. Введение в Аюрведу. Пропедевтика аюрведической медицины: монография. СПб. Изд-во «Ремедиум», 2011. 237 c. [Subotyalov M.A. Introduction to Ayurveda. Propedeutics of Ayurvedic medicine: monograph. St. Petersburg. «Remedium», 2011. 237 p.] (In Russ)

12. Суботялов М.А. Место аюрведической медицины в здравоохранении России. Бюллетень Национального НИИ общественного здоровья имени Н.A. Семашко. 2015; 3: 181-183. [Subotyalov M.A. Place of Ayurvedic medicine in the health care of Russia. [Byulleten' Nacional'nogo NII obshchestvennogo zdorov'ya imeni N.A. Semashko] Bulletin of the N.A. Semashko National Research Institute of Public Health. 2015; 3: 181-183.] (In Russ).

13. Суботялов М.А. Традиционная аюрведическая медицина: источники, история и место в современном здравоохранении: автореф. дис

... д-ра. мед. наук. М., 2014. 50 с. [Subotyalov M.A. Traditional Ayurvedic medicine: sources, history and place in modern healthcare: author's abstract ... Dr. of Sci. (Med.) M., 2014. 50 p.] (In Russ).

14. Суботялов М.А., Дружинин В.Ю. Аюрведа: источники и характеристика. М.: Философская книга, 2015. 272 с. [Subotyalov M.A., Druzhinin V.Yu. Ayurveda: sources and characteristics. M.: Philosophical book, 2015. 272 c.] (In Russ).

15. Суботялов М.А., Дружинин В.Ю. Психосоматическое направление в традиционной аюрведической медицине. Вестник Томского государственного университета. История. 2013; 4(24): 169-172. [Subotyalov M.A., Druzhinin V.Yu. Psychosomatic direction in traditional Ayurvedic medicine. [Vestnik Tomskogo gosudarstvennogo universiteta] Tomsk State University Journal. History. 2013; 4(24): 169-172.] (In Russ).

16. Manohar P.R., Sorokin O., Chacko J., Nampoothiri V. An exploratory clinical study to determine the utility of heart rate variability analysis in the assessment of dosha imbalance. Journal of Ayurveda and Integrative Medicine. 2018; 9(2): 126-130. doi: http://dx.doi. org/10.1016/j.jaim.2017.06.008. 